\title{
Stimuli with identical contextual functions taught independently become functionally equivalent
}

\author{
Luis Antonio Pérez-González • Elvira Díaz • \\ Silvia Fernández-García $\cdot$ Cristina Baizán
}

Published online: 12 February 2015

(C) Psychonomic Society, Inc. 2015

\begin{abstract}
A novel learning process that does not require stimulus associations was explored in humans. The hypothesis was that two contextual stimuli taught in separate settings, with different stimuli, become equivalent if they accomplish identical functions with regard to the relations between the stimuli presented with them. The procedure consisted of : (a) first teaching an $\mathrm{AB}$ conditional discrimination (e.g., match $\mathrm{A} 1$ to $\mathrm{B} 1$ and $\mathrm{A} 2$ to $\mathrm{B} 2$ ) and then teaching a second-order $\mathrm{XAB}$ conditional discrimination in which $\mathrm{X} 1$ indicated performing the same selections as in $\mathrm{AB}$ and $\mathrm{X} 2$ indicated selecting the alternative comparison (e.g., match $\mathrm{A} 1$ to $\mathrm{B} 2$ and $\mathrm{A} 2$ to $\mathrm{B} 1$ ); (b) repeating the procedure with completely new stimuli, YHJ, in which the functions of the Y stimuli were identical to those of $\mathrm{X}$; and (c) conducting a final probe under extinction to verify the equivalence between the $\mathrm{X}$ and the $\mathrm{Y}$ stimuli. Three experiments were conducted to explore the process and to rule out the influence of alternative variables. Out of these, 13 of the 14 participants matched the stimuli to the same contextual functions. Thus, the hypothesis was verified. These results demonstrate that humans are able to match stimuli according to their functions in relation to other stimuli. This process may be very much involved in language; for example, understanding that words or clauses that have been learned in separate contexts and with separate stimuli share the same meaning. Understanding this process may help to identify learning or developmental problems, such as those shown by persons with autism, and help to treat them.
\end{abstract}

L. A. Pérez-González $(\bowtie)$

Department of Psychology, University of Oviedo, Plaza Feijoo s/n.

Despacho 209, 33003 Oviedo, Spain

e-mail: laperez@uniovi.es

E. Díaz $\cdot$ S. Fernández-García $\cdot$ C. Baizán

School of Psychology, University of Oviedo, Oviedo, Spain
Keywords Contextual control $\cdot$ Stimulus relations $\cdot$ Stimulus equivalence $\cdot$ Associative learning $\cdot$ Functional equivalence . Language $\cdot$ Verbal behavior

\section{Introduction}

Several learning processes have unique features in that discriminative functions are acquired without direct links or associations between novel stimuli and existing conditioned or discriminative stimuli. A paradigmatic example is Harlow's (1949) learning set: He taught successive simple discriminations between two-stimuli sets to rhesus monkeys with novel stimuli in each set and found that the monkeys learned new discriminations faster and faster in spite of the fact that each stimulus set contained stimuli not presented before. This basic finding was also found in human beings with first-order (Saunders \& Spradlin, 1990, 1993) and second-order (PérezGonzález, Spradlin, \& Saunders, 2000) conditional discriminations. Another paradigmatic study that shows a process with no associations among antecedent stimuli was Vaughan's (1988). He demonstrated that pigeons reverse the function of several stimuli in a set if other stimuli indirectly related to them had reversed their function. He divided 40 slides with pictures in two sets A1, A2, A3, A4, .. and B1, B2, B3, B4, .. in such a way that the stimuli in each set did not have any common physical resemblance that could allow a person to classify any stimulus as a member of a set. The pigeons were presented with a simple successive discrimination in which pecks to slides in set A were followed by food - the positive stimuli and pecks to slides in set $B$ were extinguished - the negative stimuli (e.g., A1+, B1-, A2+, B2-, A3+, B3-). All the stimuli were presented randomly, in different orders across sessions. After reaching an accuracy criterion, he reversed the 
contingency by reinforcing pecks to slides that were previously negative and extinguished pecks to slides that were previously positive (e.g., A1-, B2+, A2-, B4+, A3-, B1+). He found that early in training, the pigeons learned the new discriminations gradually after reversals. With more training, however, pigeons were able to reverse successfully in the first session when the contingencies were changed, which indicated that when several stimuli in a set acquired a $\mathrm{S}+$ function, other stimuli in the set acquired that function without direct training. A theoretical description of these findings is that the stimuli in each set became equivalent because they shared the same function.

Yet another process related to the process studied by Vaughan is stimulus equivalence, as described by Sidman in humans (e.g., Sidman, 1994, Sidman \& Tailby, 1982) (note that Vaughan conceptualized the process he observed as a case of stimulus equivalence). In the "many to one" protocol used in Sidman's stimulus equivalence (e.g., Saunders, Drake, \& Spradlin, 1999 -see also the use with pigeons in Urcuioli,
Zentall, \& DeMarse, 1995), two conditional discriminations with common comparisons are taught. For example, in conditional discrimination $\mathrm{AB}$, selections of comparison $\mathrm{B} 1$ are reinforced in the presence of $A 1$ and selections of comparison $\mathrm{B} 2$ are reinforced in the presence of $\mathrm{A} 2$; in conditional discrimination $\mathrm{CB}$, selections of comparison $\mathrm{B} 1$ are reinforced in the presence of $\mathrm{C} 1$ and selections of comparison $\mathrm{B} 2$ are reinforced in the presence of $\mathrm{C} 2$. Further probes typically show that stimuli $\mathrm{A} 1$ and $\mathrm{C} 1$, on the one hand, and stimuli $\mathrm{A} 2$ and $\mathrm{C} 2$, on the other, become equivalent. Thus, it was the specific functions of both $\mathrm{A} 1$ and $\mathrm{C} 1$ to "indicate" that $\mathrm{B} 1$ was the correct comparison that produced the functional equivalence between $\mathrm{A} 1$ and $\mathrm{C} 1$. The outcome is similar to that found by Vaughan because stimuli $\mathrm{A}$ and $\mathrm{C}$ are not presented together before the probe. What is important is that stimuli $\mathrm{A} 1$ and $\mathrm{C} 1$, on the one hand, and $\mathrm{A} 2$ and $\mathrm{C} 2$, on the other, become equivalent because they have the same functions (see top panels of Fig. 1). The fact that two stimuli accomplish identical
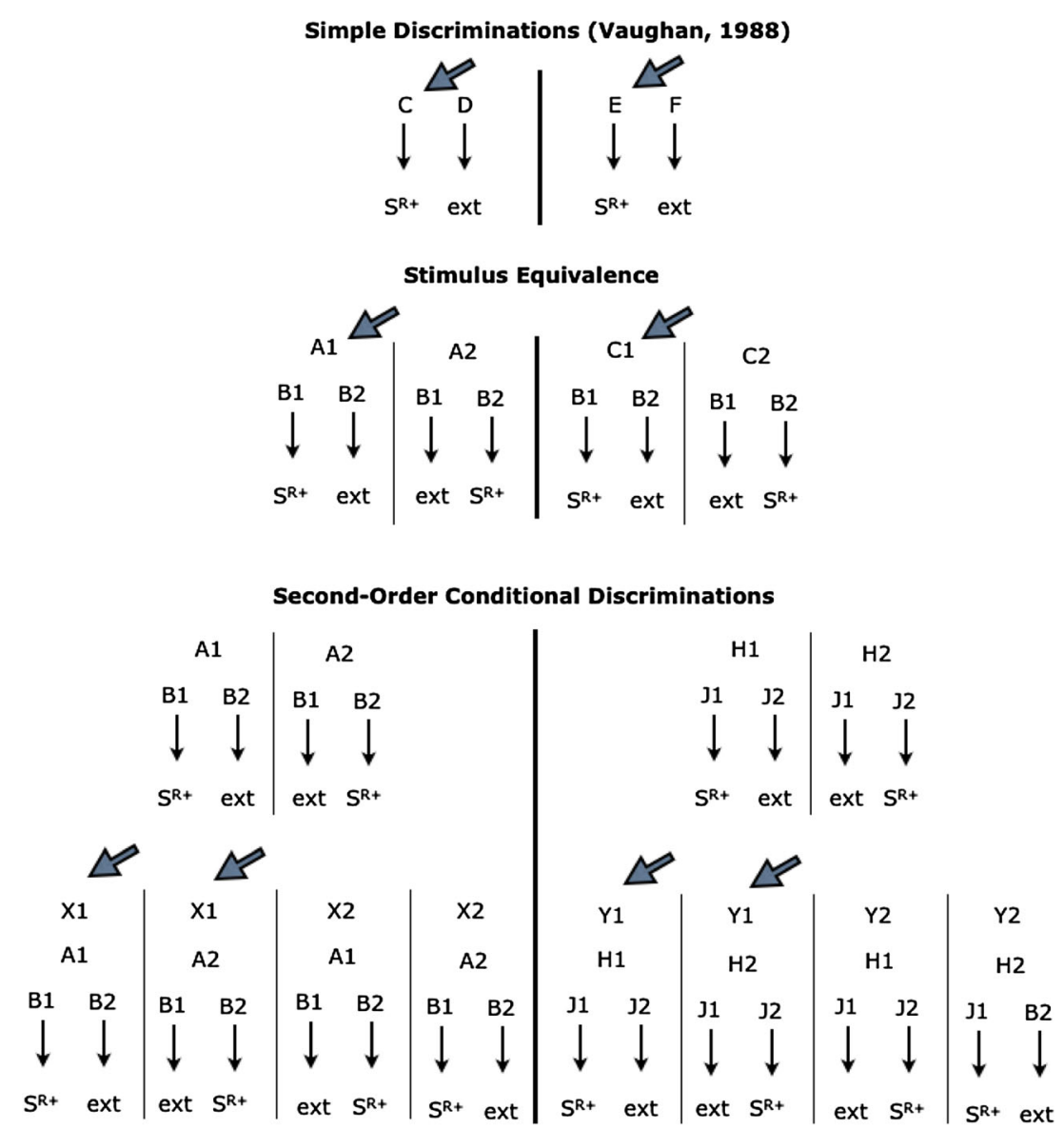

Fig. 1 Three equivalence paradigms resulting from acquiring identical functions. The top panel describes Vaughan's (1988) procedure, in which two stimuli $\mathrm{C}$ and $\mathrm{E}$ become equivalent because both indicate the reinforcement; in the reversed condition, the reinforcement was indicated by $\mathrm{D}$ and $\mathrm{F}$ and they become equivalent as well. The middle panel describes the many to one procedure for stimulus equivalence used by Saunders, Drake, and Spradlin (1999); A1 and C1 become equivalent because in its presence the selections from B1 produce the reinforcement;

the same occurs with A2 and C2 and the selection of B2. The bottom panel is based on the procedure designed by Pérez-González and Serna (2003); stimulus X1 and Y1 can become equivalent because they indicate selecting the same comparison in the presence of a sample as in the previous conditional discrimination (shown atop) in which $\mathrm{X}$ or $\mathrm{Y}$ were not presented; $\mathrm{X} 2$ and $\mathrm{Y} 2$ can become equivalent as well because both stimuli indicate selecting the alternative comparison with respect to that selected when $\mathrm{X}$ or $\mathrm{Y}$ were not presented 
functions is what makes them equivalent to one another. A theoretical explanation in terms of associative process, however, is possible in this case because it is clear that A1 was related to $\mathrm{C} 1$ because $\mathrm{A} 1$ was related to $\mathrm{B} 1$ and $\mathrm{B} 1$ was related to $\mathrm{C} 1$, and similarly for A2-B2-C2. (Similar cases of equivalence established between stimuli that have been related to common stimuli are stimulus equivalence obtained with procedures other than "many to one" and the studies on contextual control of simple discriminations ${ }^{1}$ as described by Honey \& Watt, 1999, and Molet, Miller, \& Zentall, 2011)

A process that does not require stimulus associations with features in common with Vaughan's process can be derived from transfer processes found in second-order conditional discriminations (see Fig. 1). In a second-order conditional discrimination, the relations between samples and comparisons are themselves conditional on the presence of an additional stimulus (Sidman, 1986, 1994). In the simplest preparation, a $\mathrm{XAB}$ conditional discrimination, selections of $\mathrm{B} 1$ in the presence of $\mathrm{A} 1$ and selections of $\mathrm{B} 2$ in the presence of $\mathrm{A} 2$ are reinforced only if contextual stimulus $\mathrm{X} 1$ is present. In other trials, contextual stimulus $\mathrm{X} 2$ is present and then selections of B2 (instead of B1) in the presence of A1 and selections of B2 (instead of B1) in the presence of A2 are reinforced. Thus, the relations between the $\mathrm{A}$ and $\mathrm{B}$ stimuli depend on the specific $\mathrm{X}$ stimulus present, as determined by the learning contingencies. In a study on transfer of functions of contextual stimuli in second-order conditional discriminations with children, Pérez-González and Serna (2003) found that the functions of $\mathrm{X} 1$ and $\mathrm{X} 2$ could be transferred to stimuli that had not been presented together with the $\mathrm{X}$ stimuli nor with the $\mathrm{A}$ or $\mathrm{B}$ stimuli. They first taught a conditional discrimination $A B$ with two samples and two comparisons. Thereafter they taught the XAB conditional discrimination as explained above. Note that the function of X1 was to indicate selection of the same comparison, in the presence of a given sample, as in the $\mathrm{AB}$ conditional discrimination. Together, the function of $\mathrm{X} 2$ was to indicate selection of the alternative comparison, in the presence of a given sample, to the comparison taught to be selected in the $\mathrm{AB}$ conditional discrimination. At this point, the experimental question was to find out whether stimuli X1 and X2 would demonstrate their purported functions as contextual stimuli. To that aim, the experimenters taught a conditional discrimination $\mathrm{CD}$, with novel stimuli not related to any of the previous stimuli, and probed the functions of X1 and X2 with these stimuli. All participants selected D1 in the presence of $\mathrm{C} 1$ and $\mathrm{D} 2$ in the presence of $\mathrm{C} 2$ when the contextual stimulus was X1, and they selected D2 in the presence of $\mathrm{C} 1$ and D1 in the presence of C2 when the contextual stimulus was X2. Thus, they demonstrated that the specific functions of the X1 and X2 stimuli transferred to the $\mathrm{C}$ and D stimuli,

\footnotetext{
${ }^{1}$ This type of contextual control is different to that described below for conditional discriminations.
}

which had never been presented before with A or B or with the X stimuli. Thus, the function of X1 in selecting the same as in the absence of the contextual stimuli (or the same as in the simple conditional discrimination) and the function of $\mathrm{X} 2$ in selecting the alternative comparison was demonstrated to transfer to any conditional discrimination with novel stimuli. This study was replicated and extended by Pérez-González, Álvarez, Calleja, and Fernández (2014), Pérez-González and Martínez (2007), and Serna and Pérez-González (2003). An analogous outcome with the $\mathrm{X}$ stimuli accomplishing comparison functions was found by Pérez-González (1994) and analyzed and extended by Carpentier, Smeets, and BarnesHolmes, (2000, 2002a, b), Junior and Costa (2003), Junior, Costa, Gonsales, and Golfeto (2001), and Pérez-González (2008). Of interest for the present study is this type of transfer, which cannot be explained by processes involving stimulus associations.

The unusual results that have been reported with secondorder conditional discriminations opened the door for theorizing about a new type of process that does not require stimulus associations, which consists of the acquisition of stimulus equivalence after two contextual stimuli acquire identical functions with separated stimulus sets, in line with that initiated by Vaughan but with novel and unique features. The hypothesis was that contextual stimuli with identical functions become functionally equivalent. The procedure and expected outcome was the following: First, $\mathrm{AB}$ and $\mathrm{XAB}$ conditional discriminations are taught. Note that stimulus $\mathrm{X} 1$ in $\mathrm{XAB}$ acquires the function of "indicating" to perform the same as in $\mathrm{AB}$ (e.g., select comparison $\mathrm{B} 1$ in the presence of $\mathrm{A} 1$ and comparison $\mathrm{B} 2$ in the presence of $\mathrm{A} 2$ ) and $\mathrm{X} 2$, in a similar way, acquires the function of "indicating" to select the alternative comparison with respect to $\mathrm{AB}$. The procedure is then repeated with a new stimulus set $\mathrm{YHJ}$, in which the function of a Y stimulus consists of indicating selecting the same as in HJ (i.e., to select comparison $\mathrm{J} 1$ in the presence of $\mathrm{H} 1$ and to select comparison $\mathrm{J} 2$ in the presence of $\mathrm{H} 2$ ), and the function of the other $\mathrm{Y}$ stimulus consists of indicating selecting the alternative comparison with respect to $\mathrm{HJ}$ (i.e., to select comparison $\mathrm{J} 2$ in the presence of $\mathrm{H} 1$ and to select comparison $\mathrm{J} 1$ in the presence of $\mathrm{H} 2$ ). Because the function of a $\mathrm{Y}$ stimulus is identical to the function of $\mathrm{X} 1$ and the function of the other $\mathrm{Y}$ stimulus is identical to the function of $\mathrm{X} 2$, it could be expected that a $\mathrm{Y}$ stimulus (Y1) becomes equivalent to $\mathrm{X} 1$ and the other (Y2) becomes equivalent to X2. Thus, stimuli can become equivalent because they acquire the same function in completely different contexts with completely new stimuli. This learning process would be unique with respect to these features.

The present research investigated this hypothesis in three experiments. Experiment 1 was conducted to demonstrate that this process could exist. Experiment 2 analyzed whether the 
phenomenon could occur with a simpler procedure than those used in Experiment 1. Experiment 3 analyzed the robustness of the data by excluding the influence of some potential confounding variables.

\section{Experiment 1}

The goal of Experiment 1 was to investigate the functional equivalence of contextual stimuli. For that, the procedures used by Pérez-González and Serna (2003) were replicated twice. Two stimuli were taught as contextual stimuli, and then probe tests were conducted to confirm that the functions were the same as in the original experiment; the procedures were then replicated with a completely new set of second stimuli. Finally, a probe was conducted to find out whether the two stimuli taught as contextual to the first stimulus set were equivalent to the two stimuli of the second stimulus set.
Method

\section{Participants}

Three Spanish-speaking adults participated: two males (Nico, 22 years old, and Jose, 49 years old) and one female (Ana, 52 years old). All were acquaintances of the experimenters and volunteered to participate; they did not receive information related to the purpose of the study or any monetary reward. None read or spoke German.

\section{Stimuli and discriminations}

Stimuli The stimuli were sounds, German words, and contrived visual forms (see Figs. 2, 3, and 4). All stimuli were presented by a computer. The words were about $13 \mathrm{~mm}$ high. The visual arbitrary forms measured about $30 \times 30 \mathrm{~mm}$; all visual stimuli were black and were presented over a white background on the screen.
Fig. 2 Relations between $A B$, $\mathrm{XAB}, \mathrm{CD}$, and $\mathrm{XCD}$ taught and probed in Experiment 1. Each panel shows the contextual stimulus, the sample, and the comparisons presented in a trial. Stimuli presented in brackets indicate that they were sounds. Plus signs indicate the comparison that selection reinforced. Question marks indicate the comparison that selection considered correct in the probes

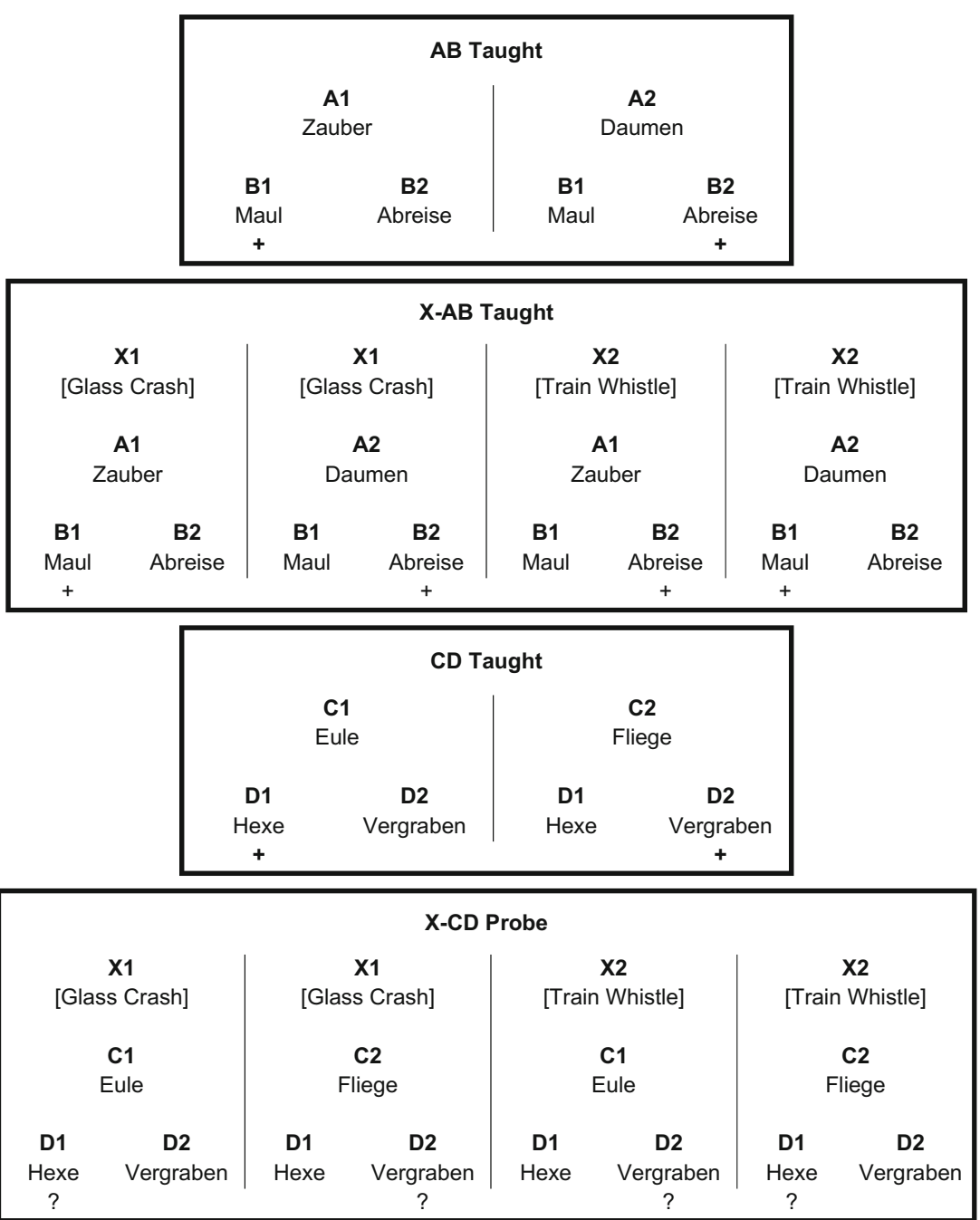


Fig. 3 Relations between HJ, YHJ, KL, and YKL taught and probed in Experiment 1. See caption to Fig. 2
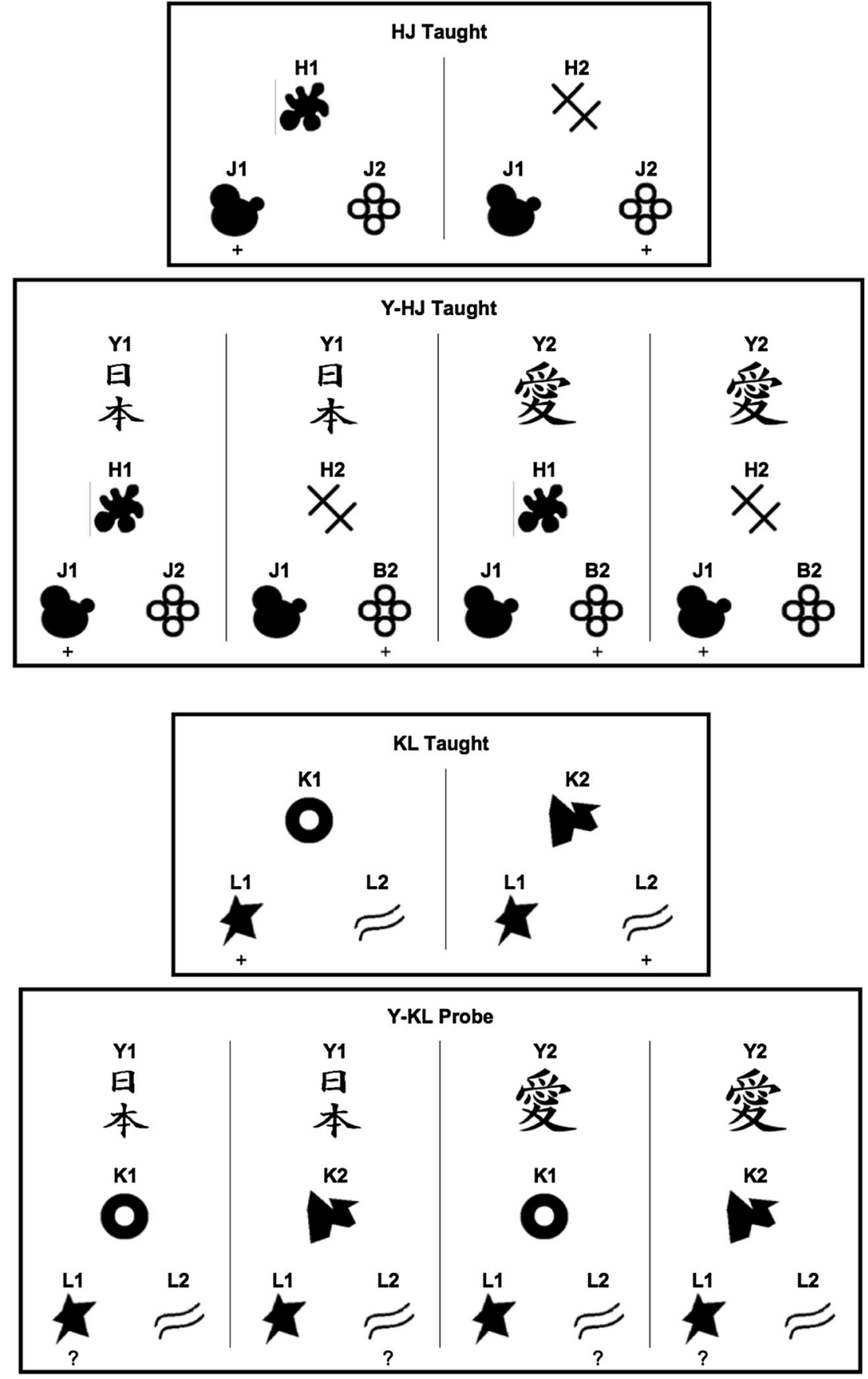

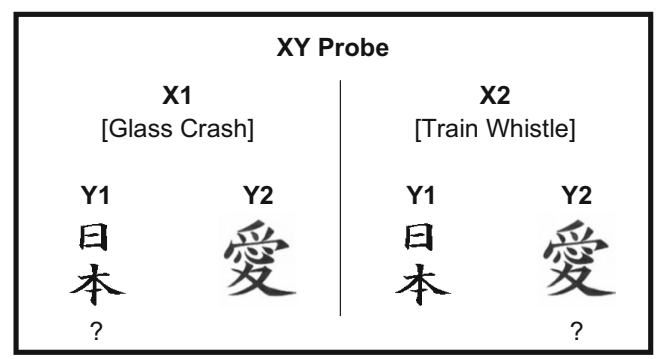

Fig. 4 Relations XY probed in Experiment 1. See caption to Fig. 2
Discriminations There were simple and second-order conditional discriminations. In simple conditional discriminations, two forms alternated randomly as samples (e.g., A1 and A2) and another two forms were the comparisons (e.g., B1 and $\mathrm{B} 2)$. For the $\mathrm{AB}$ conditional discrimination, in the presence of $\mathrm{A} 1, \mathrm{~B} 1$ was the correct comparison; in the presence of $\mathrm{A} 2$, $\mathrm{B} 2$ was the correct comparison. The CD, HJ, KL, and YX conditional discriminations were analogous to $\mathrm{AB}$ (as shown in Figs. 2, 3, and 4). In second-order conditional discriminations, two stimuli alternated randomly as 
contextual stimuli and samples and comparisons were as in the simple conditional discriminations. For the XAB conditional discrimination, in the presence of $\mathrm{X} 1$ and $\mathrm{A} 1, \mathrm{~B} 1$ was the correct comparison; in the presence of $\mathrm{X} 1$ and $\mathrm{A} 2, \mathrm{~B} 2$ was the correct comparison; in the presence of $\mathrm{X} 2$ and $\mathrm{A} 1, \mathrm{~B} 2$ was the correct comparison; in the presence of $\mathrm{X} 2$ and $\mathrm{A} 2, \mathrm{~B} 1$ was the correct comparison (see Fig. 2). The XCD, YHJ, and YKL second-order conditional discriminations were analogous to XAB (see Figs. 2 and 3).

\section{Procedure}

Setting and instructions The sessions were conducted with a portable computer. A Power Point presentation was programed to present the figures. On each trial, the contextual stimuli (if applied) and the sample appeared in the upper central part of the screen. About $3 \mathrm{~cm}$ below them, the two comparisons were presented, one on the left and the other on the right, separated by $6 \mathrm{~cm}$. When the contextual stimulus was a sound, it started just after presenting the visual stimulus. The experimenter was seated beside the participant; thus, the participant did not see the face of the experimenter. The experimenter initiated each trial by pressing the computer keyboard. She registered the participant's response on a form that was out of the participant's sight. Another experimenter or a person well trained in observing responses and collecting data registered the participant's responses for computing reliability (see Interobserver Agreement below). Once the experimenter and the participant were seated, the experimenter told the participant: "Thank you for participating in this experiment. We are going to present some figures on the screen. Then, you must touch over a figure. Sometimes, I will inform you about whether your selection has been right or not. The experiment consists of responding correctly as many times as possible." If the participant asked questions, the experimenter responded by clarifying the instructions - other questions were not answered.

Procedure overview The $\mathrm{AB}$ and $\mathrm{XAB}$ conditional discriminations were taught first. The $\mathrm{CD}$ conditional discrimination was then taught and the transfer of the contextual functions of $\mathrm{X} 1$ and $\mathrm{X} 2$ with the $\mathrm{CD}$ stimuli was probed, without differential reinforcement - this was the probe of the XCD conditional discrimination (see below, Parts 1 to 4). If the XCD relations did not emerge with a participant, then the entire procedure was repeated with that participant. Once the XCD emergence was verified with the three participants, the procedures with $\mathrm{AB}, \mathrm{XAB}, \mathrm{CD}$, and $\mathrm{XCD}$ were repeated. Thereafter, the HJ, $\mathrm{YHJ}$, and KL conditional discriminations were taught, and the YKL conditional discrimination was probed. Stimuli Y1 and $\mathrm{Y} 2$ had identical functions to $\mathrm{X} 1$ and $\mathrm{X} 2$, respectively. Finally, the crucial probe of the equivalence between $\mathrm{X}$ and $\mathrm{Y}$ stimuli was conducted with the $\mathrm{XY}$ conditional discrimination probe. An overview of the procedures and results appear in Appendix A.

General procedure During the teaching phases, every time the participant selected the correct comparison, the experimenter presented approval statements such as "good," "excellent," "perfect," "good job," or "you're doing great." Further responses from the participants indicated that these expressions worked as reinforcers within the context of this study. If the participant selected the incorrect comparison, the experimenter responded with "no." A period of $10 \mathrm{~s}$ was allocated for responding, but participants selected a comparison before that time in all trials. During probe tests, there were nondifferential consequences for correct and incorrect responding - after the participant responded, the next trial was presented. The next trial started after an intertrial interval of about $5 \mathrm{~s}$.

Part 1: AB teaching The abbreviated combined blocking procedure (Rodríguez-Mori \& Pérez-González, 2005) was used to teach the $\mathrm{AB}$ conditional discrimination in four phases. In Phase 1 (A1B1), stimulus A1 was presented as the sample in all trials; B1 was placed on the left and B2 was placed on the right. On the first two trials, the experimenter indicated to the participant that $\mathrm{B} 1$ was the correct comparison by saying, "Point here" and placing her finger on B1 (this was a prompt). After the third trial, the prompt was not presented; only the stimuli was presented on the screen. After three consecutive correct responses, the experiment continued on Phase 2. Phase 2 was as Phase 1, but A2 was presented as the sample in all trials and the correct comparison was B2. In Phase 3, stimuli A1 and A2 alternated randomly as samples, with the restriction that each sample was presented twice in every four trials. Stimuli B1 and B2 were presented as in Phases 1 and 2. No prompt was presented. After eight consecutive correct responses, the experiment continued to the next phase. Phase 4 was the same as Phase 3, except for that the left-right location of stimuli B1 and B2 was random, with the restriction that each comparison was located twice on each location in every four trials.

Part 2: $X A B$ teaching This was taught in nine Phases (see Appendix A). Phases 1 to 4 were identical to Phases 1 to 4 of the $\mathrm{AB}$ teaching, with the presentation of contextual stimulus X1 (i.e., a sound of glass crashing) just after presenting the samples and the comparisons, in every trial.

Phases 5-8 were the same as Phases $1-4$, except that contextual stimulus X2 (a train whistle sound) was presented in all trials, instead of X1. (As explained above, B2 was correct when $\mathrm{X} 2$ and $\mathrm{A} 1$ were presented and $\mathrm{B} 1$ was correct when $\mathrm{X} 2$ and $\mathrm{A} 2$ were presented.) In Phase 9, $X A B$ was taught. The four combinations resulting from combining $\mathrm{X} 1$ and $\mathrm{X} 2$ with $\mathrm{A} 1$ and $\mathrm{A} 2$ were presented randomly with the restriction that each combination was presented once every four trials. 
Stimuli B1 and B2 appeared as comparisons at random locations as in the previous phases. After eight consecutive correct responses, the experiment continued in Part 3.

Part 3: $C D$ teaching This was identical to teaching $\mathrm{AB}$, with $\mathrm{C}$ stimuli presented as samples and D stimuli presented as comparisons.

Part 4: XCD probe The four combinations of $\mathrm{X}$ and $\mathrm{C}$ stimuli (X1C1, X1C2, X2C1, and X2C2) were presented randomly every four trials. Stimuli D1 and D2 were presented as comparisons at random left-right locations, with the restriction that each stimulus appeared twice in each location every four trials. After 16 trials, the probe finished. The criterion for considering the emergence of the XCD relations was performing at least 14 correct responses.

Parts 5 to 8: HJ, YHJ, and KL teaching and YKL probe These were identical to Parts 1 to 4, respectively, but the HJ, YHJ, and $\mathrm{KL}$ conditional discriminations were taught, and the YKL conditional discrimination was probed. Contextual stimuli Y (visual forms) were presented above the sample in every trial of the YHJ and the YKL conditional discriminations.

Part 9: X-Yprobe Samples X1 or X2 were presented randomly, with the restriction that each one was presented twice in every four trials; Y1 and Y2 were the comparisons; they were presented randomly at left-right locations, with the restriction that each stimulus appeared twice on the left and twice on the right every four trials. There were no differential consequences for responding. The probe finished after presenting 16 trials. The criterion for considering the emergence of the $\mathrm{XY}$ relations was to select $\mathrm{Y} 1$ in the presence of $\mathrm{X} 1$ and $\mathrm{Y} 2$ in the presence of $\mathrm{X} 2$ in at least 14 of the 16 trials or in the last eight trials.

Response definition, data recording, interobserver agreement, and procedural integrity A response was recorded when the participant touched over one of the comparisons. For all trials, an observer registered the participant's responses for purposes of calculating interobserver agreement as a measure of recording reliability. In addition, the observer verified that the procedure was implemented according to the experimental plan. They registered a total of 1,204 responses. The two observers agreed on 1,203 responses; thus the interobserver agreement was $99.92 \%$. The procedure was always implemented correctly.

Results

The overall results are shown in Appendices A and B. The results from the probes are shown in Table 1 . The three participants learned first the $\mathrm{AB}, \mathrm{XAB}$, and $\mathrm{CD}$ conditional
Table 1 Correct responses in 16 trials in each probe in Experiment 1. Participant Ana received two sessions until she reached the criterion in $\mathrm{XCD}$

\begin{tabular}{lllll}
\hline Probe & \multicolumn{3}{l}{ Participant } & \\
\cline { 2 - 5 } & Nico & Jose & Ana 1 & Ana 2 \\
\hline Part 6: XCD Probe & 16 & 16 & 9 & 16 \\
Part 4: XCD Probe -repetition & 16 & 16 & 16 & \\
Part 8: YKL Probe & 16 & 16 & 16 & \\
Part 9: XY Probe & 16 & 16 & 16 & \\
\hline
\end{tabular}

discriminations. Jose and Nico learned these conditional discriminations in 115 and 121 trials, with most responses correct (.98 and .95, respectively). Ana learned these in 143 trials (.78 correct). In Phase 9 of Part 2, XAB teaching, she made an unusual number of incorrect responses, as she responded incorrectly in all 29 first trials; then she reverted selections and immediately reached the criterion by making eight consecutive correct responses. In the XCD probe, two participants demonstrated the emergence of the XCD conditional discrimination, as they responded according to the definition of emergence in all 16 trials. The third participant, Ana, responded in accordance with that definition in nine of the 16 trials. Therefore, the entire procedure with stimuli $\mathrm{AB}$ and $\mathrm{CD}$ was repeated and she demonstrated the emergence of the XCD relations in the second probe with all 16 responses according to the definition of emergence.

After the three participants demonstrated the emergence of the XCD relations, the whole procedure was repeated with the three participants (see Appendix B). They responded correctly in all but one teaching trial. They demonstrated transfer of contextual control with stimuli X in the XCD conditional discrimination for the second time. The entire procedure was then repeated with stimuli $\mathrm{H}, \mathrm{J}, \mathrm{K}, \mathrm{L}$, and Y. They learned the HJ, YHJ, and KL conditional discriminations with no errors. They also responded correctly in all 16 trials of the YKL conditional discrimination probe. Thus, they demonstrated transfer of contextual control with the Y stimuli as well.

In the $\mathrm{XY}$ conditional discrimination probe, the three participants matched $\mathrm{X} 1$ to $\mathrm{Y} 1$ and $\mathrm{X} 2$ to $\mathrm{Y} 2$ in all trials. Thus, they responded according to the hypothesis in all trials.

\section{Discussion}

The goal of Experiment 1 was to investigate the functional equivalence of contextual stimuli taught independently. Stimuli that were initially neutral (X1 and X2) acquired specific contextual functions when taught and probed with a set of stimuli; thereafter, additional initially neutral stimuli (Y1 and $\mathrm{Y} 2$ ), unrelated to $\mathrm{X} 1$ and $\mathrm{X} 2$, acquired identical functions as the $\mathrm{X}$ stimuli. Specifically, the function acquired by $\mathrm{X} 1$ and 
Y1 was that of indicating the selection of the same comparison, in the presence of each sample, as in the absence of a contextual stimulus; the function acquired by $\mathrm{X} 2$ and $\mathrm{Y} 2$ was that of indicating the selection of the alternative function. The final probe showed that all participants reliably related the stimuli with identical functions: $\mathrm{X} 1$ with $\mathrm{Y} 1$ and $\mathrm{X} 2$ with Y2. Thus, the main hypothesis of the present study was confirmed. The learning process involved is described here for the first time. Moreover, this outcome cannot be explained by associative processes.

It is worth mentioning that the stimuli that became functionally equivalent were of a different sensory modality stimuli $\mathrm{X}$ were auditory and stimuli $\mathrm{Y}$ were visual. Once more, the function of the stimuli seems to affect behavior more than the stimulus modality.

Additionally, the present results replicated those demonstrated by Pérez-González and Serna (2003) and PérezGonzález and Martínez (2007). The present study was demonstrated with both visual and auditory stimuli. Thus, the process consisting of transferring specific contextual functions acquired additional empirical evidence.

\section{Experiment 2}

Experiment 1 demonstrated the functional equivalence between $\mathrm{X}$ and $\mathrm{Y}$ stimuli after the participants (a) have learned these functions (in XAB and YHJ) and (b) have demonstrated the transfer of these functions with novel stimuli, as shown in the XCD and the YKL probes. The functional equivalence between $\mathrm{X}$ and $\mathrm{Y}$ stimuli could have been produced by learning the functions alone or by learning the functions plus the additional experience of demonstrating the transfer in the probes with novel stimuli (i.e., $\mathrm{CD}$ and $\mathrm{KL}$ ). This hypothesis is supported, for example, by the fact that even though there is no reinforcement during the probes, it has been often observed that probing alone affects further emergence (e.g., PérezGonzález, 1994). The main goal of Experiment 2 was to find out whether the transfer probe is necessary for the acquisition of functional equivalence among the contextual stimuli. A secondary goal was to replicate the phenomenon with additional participants.

\section{Method}

\section{Participants}

Three Spanish-speaking adults participated: Two males (Camilo, 49 years old, and Julio, 22 years old) and one female (Sara, 20 years old). They had the same characteristics as those in Experiment 1.

\section{Materials and procedure}

The procedure was a shortened version of Experiment 1 (see Appendix C). Specifically, conditional discriminations AB, $\mathrm{XAB}, \mathrm{HJ}$, and $\mathrm{YHJ}$ were taught and the probe for the equivalence among stimuli $\mathrm{X}$ and $\mathrm{Y}$ was conducted (Parts 1, 2, 5, 6, and 9 of Experiment 1, renamed as Parts 1 to 5 in Experiment 2 - see panels $\mathrm{AB}$ and $\mathrm{XAB}$ in Fig. 2, panels $\mathrm{HJ}$ and $\mathrm{YHJ}$ in Fig. 3 and Fig. 4).

The experimenter and the observer recorded all 580 trials. The Interobserver Agreement was $99.48 \%$ and the procedure was implemented according to the experimental plan in all trials.

\section{Results}

The three participants learned the $\mathrm{AB}, \mathrm{XAB}$, and $\mathrm{HJ}$ and $\mathrm{YHJ}$ conditional discriminations with most responses correct (range across participants 93-100\%) (the overall results appear in Appendix C). In the XY conditional discrimination probe, two of the three participants responded according to the hypothesis of functional equivalence between $\mathrm{X} 1$ and $\mathrm{Y} 1$ and between $\mathrm{X} 2$ and Y2: Camilo emitted all 16 responses correctly and Julio emitted 14 out of 16 correct responses. The third participant, Sara, responded according to this criterion in 13 out of 16 responses (81\%). Julio's two errors and Sara's three errors were in the first five trials of the probe. Therefore, they responded correctly in all the 11 last trials.

\section{Discussion}

The participants' performance indicates that probing the transfer of functions of the contextual stimuli is not necessary for the acquisition of the equivalence. Moreover, the results of Experiments 1 and 2 suggest that this type of functional equivalence is relatively easy to acquire, at least in adults: All six participants demonstrated this process.

\section{Experiment 3}

The goal of Experiment 3 was to collect additional evidence of the learning process found in Experiments 1 and 2. The same procedure as in Experiments 1 and 2 was conducted for all participants. The results are robust and procedures similar to those used in the present study have been broadly replicated across laboratories and stimuli. There exists, however, a remote possibility that the acquired equivalence could have resulted from participants' idiosyncratic stimulus preferences or relations. Thus, the participants would have selected visual stimulus $\mathrm{Y} 1$ in the presence of sound $\mathrm{X} 1$ and visual stimulus $\mathrm{Y} 2$ in the presence of sound $\mathrm{X} 2$ due to personal preferences. 
The possibility is remote: Using the same stimulus set with all participants is customary in virtually all the studies published on stimulus equivalence, the results have been replicated with a myriad of stimuli, and no preference was found on the part of the participants that could overshadow the main effect of the manipulated variables. The first goal of Experiment 3 was verifying that stimulus preference does not influence the results.

A second possibility is that the acquired equivalence did not result from contextual functions, but rather the order in which the stimuli were taught. Notice that X1 was introduced first (in Parts 1-4 of the XAB teaching, Part 2 of Experiment 1) and then $X 2$ was introduced (in Parts 5-8). The same occurred with Y1 and Y2: Y1 was introduced first (in Parts 1-4 of YHJ teaching, in Part 6 of Experiment 1). Thus, X1 and Y1 could have become equivalent because they were the first contextual stimuli presented to the participant in each part of the experiment, rather than because of their contextual functions, but because their teaching order. Similarly, X2 and Y2 could have become equivalent because they were presented after X1 and Y1, respectively. In sum, participants could have matched the first with the first and the second with the second. Notice that the possible occurrence of this phenomenon does not rule out stimulus equivalence; instead, it would indicate that the stimuli became equivalent by order of learning rather than by contextual functions. In any case, it was considered important to analyze the functions responsible for equivalence class formation.

Experiment 3, thus, replicated the procedures of Experiments 1 and 2, but three variables were manipulated. The goals were ruling out the influence of stimulus preference on the outcomes, on the one hand, and clarifying the specific stimulus function that determined equivalence, on the other.

\section{Method}

\section{Participants}

Eight Spanish-speaking adults participated. Their fictitious names, ages, and sexes appear in Table 2. They had the same characteristics as those in Experiments 1 and 2.

Stimuli and procedure

Stimuli These were the same as in Experiments 1 and 2, except that the Y stimuli were modified to facilitate learning. They are shown in Fig. 5.

Procedure The Power Point software was programmed to allow the participant to select the comparison with the computer mouse and to present the consequences automatically; the consequences were "very good" when the participant selected the correct comparison and "bad" when the participant
Table 2 Correct responses in the 16 trials of the XY probe in Experiment 3. The number that follows the participant's name indicates the condition that they received; in the line below that, (a) the age in years and sex (m: male; f: female), (b) the Y stimulus presented first (Y1 or Y2), (c) the drawing assigned to $\mathrm{Y} 1$ (A or B), and (d) the sound stimulus assigned to $\mathrm{X} 1$ are shown

\begin{tabular}{|c|c|c|c|c|c|c|c|}
\hline \multicolumn{8}{|c|}{ Participant and condition } \\
\hline $\begin{array}{l}\text { Flora-1 } \\
23-\mathrm{F}\end{array}$ & $\begin{array}{l}\text { Sara-2 } \\
18-\mathrm{F}\end{array}$ & $\begin{array}{l}\text { Lola-3 } \\
23-\mathrm{F}\end{array}$ & $\begin{array}{l}\text { Andrea-4 } \\
22-\mathrm{F}\end{array}$ & $\begin{array}{l}\text { David-5 } \\
18-\mathrm{M}\end{array}$ & $\begin{array}{l}\text { Alba-6 } \\
20-\mathrm{F}\end{array}$ & $\begin{array}{l}\text { Mario-7 } \\
\text { 22-M }\end{array}$ & $\begin{array}{l}\text { Sara-8 } \\
23-\mathrm{F}\end{array}$ \\
\hline Y1 & Y1 & Y1 & Y1 & Y2 & $\mathrm{Y} 2$ & Y2 & $\mathrm{Y} 2$ \\
\hline A & $\mathrm{A}$ & $\mathrm{B}$ & $\mathrm{B}$ & A & $\mathrm{A}$ & $\mathrm{B}$ & $\mathrm{B}$ \\
\hline [train] & [glass] & [train] & [glass] & [train] & [glass] & [train] & [glass] \\
\hline 16 & 16 & 16 & 16 & 0 & 16 & 16 & 16 \\
\hline
\end{tabular}

selected the incorrect comparison. The remaining procedures were as for Experiment 2. In addition, three variables were manipulated across participants. Thus, each participant was randomly assigned to one of the eight conditions that result from combining the two factors of each variable detailed below (see Table 2).

Variable 1: Order of presentation of Y1 and Y2 Factor 1: Stimulus Y1 was taught first and stimulus Y2 was taught second, in Phases 1-4 of Part 4, just as in Experiment 2. Factor 2: Stimulus Y2 was taught first and stimulus Y1 was presented second. Thus, Phases 5-8 of Part 4 were conducted first and Phases 1-4 of Part 4 were conducted next. Phase 9 of Part 4, in which Y1 and Y2 were presented quasi-randomly across trials, was presented last to all participants, i.e., regardless of the Factor.

Variable 2: Stimuli assigned to Y1 and to Y2 Factor 1: Drawing A was Y1 and Drawing B was Y2 (see Drawings $\mathrm{A}$ and $\mathrm{B}$ in Fig. 5). Factor 2: Drawing B was now $\mathrm{Y} 1$ and Drawing A was Y2.

Variable 3: Stimuli assigned to X1 and to X2 Factor 1: Glass crash sound as X1 and train whistle sound as X2. Factor 2: Train whistle sound as X1 and glass crash sound as X2.

The manipulation of variables 2 and 3 resulted in different equivalences among the $\mathrm{X}$ and the $\mathrm{Y}$ stimuli: For half participants, Drawing A in the YHJ conditional discrimination accomplished the same function as the train sound in $\mathrm{XAB}$; for the other half, Drawing A accomplished the same function as the glass crash sound in XAB. The selections of the stimuli with the same functions were considered correct in the $\mathrm{XY}$ probe. This way, a possible bias due to the use of specific stimuli was ruled out.

Response definition, data recording, and interobserver agreement These procedures were very similar to those in 
Fig. 5 Stimuli used in Experiment 3, as they were presented in the XY probe. Stimuli presented in brackets indicate that they were sounds. For half of the participants, selections of $Y 1$ in the presence of $\mathrm{X} 1$ and selections of $\mathrm{Y} 2$ in the presence of $\mathrm{X} 2$ were considered correct. For the other half, selections of $\mathrm{Y} 2$ in the presence of $\mathrm{X} 1$ and selections of $\mathrm{Y} 1$ in the presence of X2 were considered correct
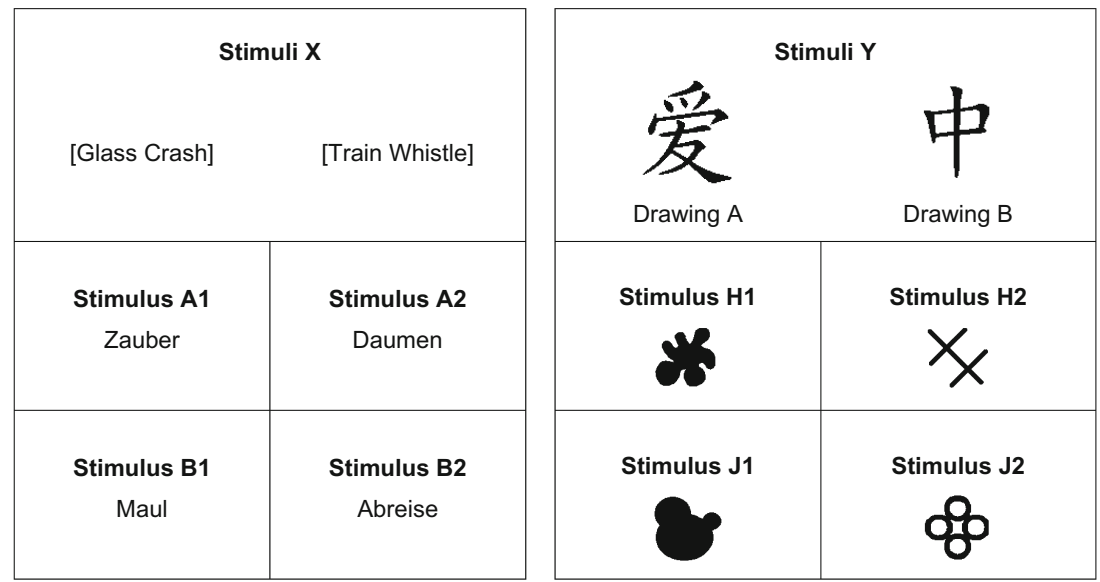

Experiments 1 and 2. Therefore, for easy data analysis, matching each $\mathrm{X}$ stimulus to the $\mathrm{Y}$ stimulus with the same contextual function was considered correct. Thus, in four participants (Conditions 5-8), a $100 \%$ correct selection in the $\mathrm{XY}$ probe would indicate stimulus equivalence with stimuli that accomplished the same contextual functions; in these four participants, a score of $0 \%$ correct in the XY probe would indicate stimulus equivalence with stimuli that were taught in the same order (equivalence class of first and equivalence class of second). For the remaining four participants (Conditions 1-4), class formation would occur only if they scored around $100 \%$ in the $\mathrm{XY}$ probe and the equivalence would have been produced either by the stimuli sharing contextual functions or by sharing order. In addition to the data during discrimination teaching and probing, a post-session informal interview was conducted with the participants in which the experimenters asked about their respondes in the probes. The consistency between their selection responses and their explanations provided supplementary data for the sources of the equivalence. Interobserver agreement was 100 $\%$ and the procedure was implemented according to the experimental plan in all trials.

\section{Results}

The overall results are shown in Appendix D. The results of the final probe are shown in Table 2. The eight participants learned the $\mathrm{AB}, \mathrm{XAB}$, and $\mathrm{HJ}$ conditional discriminations with most responses correct (range across participants from 95-100 \%). In the XY conditional discrimination probe, seven of the eight participants responded according to the hypothesis of functional equivalence between $\mathrm{X} 1$ and $\mathrm{Y} 1$ and between $\mathrm{X} 2$ and $\mathrm{Y} 2$ due to the stimuli sharing contextual functions: They demonstrated all 16 responses according to this hypothesis. The participant in condition 5 (Y2 first, drawing A, train whistle sound), David, selected consistently Y2 in the presence of $\mathrm{X} 1$ and selected $\mathrm{Y} 1$ in the presence of X2. The post- session interview revealed that he matched the two stimuli that were taught first and the two stimuli that were taught second, regardless of the contextual functions of the $\mathrm{X}$ and $\mathrm{Y}$ stimuli in the $\mathrm{XAB}$ and the YHJ conditional discriminations.

In the post-session interview, the seven participants who responded in accordance with the hypothesis of class formation due to contextual functions said that they matched the $\mathrm{X}$ stimulus to the $\mathrm{Y}$ stimulus with the same contextual function. The participant who did not respond in accordance with that hypothesis said that he matched stimulus X1, presented before stimulus X2, to stimulus $\mathrm{Y} 2$, presented before $\mathrm{Y} 1$, and that he matched stimulus $\mathrm{X} 2$ to stimulus $\mathrm{Y} 1$, which were presented last; therefore, this participant demonstrated class formation produced by the teaching order of the stimuli.

\section{Discussion}

Seven of the eight participants responded in the $\mathrm{XY}$ probe according to the hypothesis of class formation with stimuli that share contextual functions; that is, they matched the $\mathrm{X}$ and $\mathrm{Y}$ stimuli according to the functions in the $\mathrm{XAB}$ and the YHJ conditional discriminations. Moreover, the postintervention interview revealed that they matched the stimuli according to these contextual functions. The results of the eighth participant (from condition 5) and the post-session interview with him revealed that he matched the $\mathrm{X}$ stimuli to the $\mathrm{Y}$ stimuli according to the teaching order. A serendipitous finding of these data is that yet another source of stimulus equivalence could be the order of stimulus presentation. That is, people can form equivalences between stimuli according to the order in which they were taught. Further research is needed to examine this hypothesis. The results of all participants in Experiment 3 replicated those obtained with three participants from Experiment 2. They also ruled out the influence of extraneous variables related to matching stimuli according to the properties of the stimuli. 


\section{General discussion}

A total of 13 of the 14 participants who participated in Experiments 1-3 demonstrated matching of stimuli with identical contextual functions. Thus, the initial hypothesis of the present study was confirmed. Results demonstrate a learning process of stimulus equivalence by means of stimuli sharing contextual functions. The process was demonstrated with two procedures. The one used in Experiment 1 consisted of teaching specific functions for contextual stimuli (in XAB) and probing the transfer of these functions to novel stimuli (in XCD) - following the same procedure with the Y stimuli. The procedure used in Experiments 2 and 3 consisted of teaching only the functions, with no transfer probes. Thus, all the results considered, the phenomenon was robust. Moreover, the remaining participant (the one in condition 5 of Experiment 3) also demonstrated class formation according to teaching order. Thus, all participants formed equivalences.

The stimulus equivalence process was observed with transfer probes of contextual stimuli $\mathrm{X}$ and $\mathrm{Y}$ in Experiment 1, as well as in the absence of these probes, in Experiments 2 and 3. Few differences were observed regarding the emergence of the $\mathrm{XY}$ functional equivalence probe. These results indicated that the transfer probes are not necessary. It is unknown, however, whether conducting the transfer probes could have an effect on the acquisition of equivalence. In fact, all participants who received the transfer probes in Experiment 1 responded with 16 out of 16 correct in the XY probe; in contrast, two of the three participants who did not receive the probes in Experiment 2 made some errors in the XY probe. These differences are consistent with the hypothesis that it may be very likely that the transfer probe could strengthen functional stimulus equivalence formation. Future research is needed to address this question.

The process observed has unique features, different from the features observed in Vaughan's (1988) and stimulus equivalence preparations. In fact, $\mathrm{X}$ and $\mathrm{Y}$ stimuli used in the present study became equivalent because of their functions in relation to the other stimuli: Stimulus X1 had in XAB the function of signaling to select the same comparison in the presence of each sample as in $\mathrm{AB}$, identical to the function of stimulus Y1 in YCD and CD. Moreover, stimulus X2 in $\mathrm{XAB}$ and stimulus $\mathrm{Y} 2$ in $\mathrm{YCD}$ had the function of signaling to select the alternative comparison. Thus, the function was related to signaling the same or different responding in the presence of the remaining stimuli. This feature is unique and contrasts with the functions in Vaughan's and stimulus equivalence preparations: First, stimuli became equivalent in Vaughan's procedure because all the stimuli in a class signaled reinforcement (e.g., they were followed by the reinforcer within a session). Second, stimuli become equivalent in stimulus equivalence preparations (e.g., Saunders et al. 1999), because they were correlated with a third stimulus in a conditional discrimination (e.g., A1 becomes of the same class as $\mathrm{C} 1$ because the presentation of $\mathrm{A} 1$ and the selection of $\mathrm{B} 1$ leads to the reinforcer and the same happens with the presentation and $\mathrm{C} 1$ and the selection of B1). Moreover, the three observed processes are variants of a unique general process consisting of the stimuli that share a specific function forming functional stimulus equivalence. In other words, all three are processes of a general process that results in functional equivalence classes.

All the procedures that result in functional stimulus equivalence establish a partition among the stimuli. The stimuli in each stimulus set belong to the same class and they belong to a different class from the stimuli in other set. In Vaughan's procedure, the 40 slides were divided into two sets; responses to 20 slides were either reinforced or extinguished altogether and the alternative consequence occurred with the other 20 slides; the partition established two sets with 20 slides each. The stimuli in a set were equivalent and they were not equivalent to any stimuli in the other set. In stimulus equivalence that results from teaching conditional discriminations with three samples and three comparisons, for example, stimuli A1, $\mathrm{B} 1$, and $\mathrm{C} 1$ belong to a set, $\mathrm{A} 2, \mathrm{~B} 2$, and $\mathrm{C} 2$ belong to a second one, and $\mathrm{A} 3, \mathrm{~B} 3$, and $\mathrm{C} 3$ belong to the third one. $\mathrm{A} 1, \mathrm{~B} 1$, and $\mathrm{C} 1$ are equivalent stimuli and they are not equivalent to the remaining stimuli $\mathrm{A} 2, \mathrm{~A} 3, \mathrm{~B} 2, \mathrm{~B} 3, \mathrm{C} 2$, and $\mathrm{C} 3$ (the same happens with $\mathrm{A} 2, \mathrm{~B} 2$, and $\mathrm{C} 2$, that belong to another set or class, and A3, B3, C3, that belong to still another set or class). In the present study, procedures established a partition among the $\mathrm{X}$ and $\mathrm{Y}$ stimuli: $\mathrm{X} 1$ and $\mathrm{Y} 1$ in a set, and $\mathrm{X} 2$ and $\mathrm{Y} 2$ in the other set. This feature is common to the three procedures discussed here. The procedures in the present study also resulted in an important uniqueness regarding partitioning: Whereas a partition was established among the $\mathrm{X}$ and $\mathrm{Y}$ stimuli, the remaining stimuli were excluded from this partition no stimuli (such as A, B, H, or J in Experiments 2 or 3, or even these stimuli and stimuli $\mathrm{C}, \mathrm{D}, \mathrm{K}$, and $\mathrm{L}$ in Experiment 1) belonged to the same class as the $\mathrm{X}$ or $\mathrm{Y}$ stimuli (see PérezGonzález \& Serna, 2003).

A further analysis in terms of stimulus equivalence reveals the complexity of relations between all the stimuli in the study. The AB conditional discrimination could have established a partition among the $\mathrm{A}$ and $\mathrm{B}$ stimuli; although it was not tested (among other reasons, because symmetry is not necessary for the emergence of the XCD or the YKL relations shown in Experiment 1), it can be argued that that partition resulted in two separate classes (A1-B1 and A2-B2). The CD conditional discrimination shown in Experiment 3 could have established a partition among the $\mathrm{C}$ and $\mathrm{D}$ stimuli in two classes (C1-D1 and C2-D2) for the same reason. The A and B stimuli, on the one hand, and the $\mathrm{C}$ and $\mathrm{D}$ stimuli, on the other, were not related to one another; therefore, it is unlikely that any A or $\mathrm{B}$ stimulus belongs to the same class as any of the $\mathrm{C}$ or $\mathrm{D}$ stimuli (see a discussion on this topic in Pérez-González \& Serna, 2003). Therefore, in Experiment 3 of the present study, 
three partitions among the stimuli could have been established, each one involving different stimuli, and forming six separate, independent classes. Even more, in Experiment 1 , five partitions among the stimuli could have been established, and ten independent classes could have been formed. The specific probes to verify this hypothesis, however, were not conducted in the scope of the present research. Further studies should be designed to answer this question.

Similar to the process observed by Vaughan (1988), in the present study, equivalence was formed between stimuli that never appeared together or that did not appear with common stimuli. With regard to learning mechanisms, stimulus equivalence may result initially from associative processes, because the stimuli that become members of a class have been presented together (e.g., in the case of symmetry) or with a third stimulus (e.g., $\mathrm{A} 1$ is presented with $\mathrm{B} 1$ and $\mathrm{B} 1$ with $\mathrm{C} 1$, which results in the A1-C1 relation) (see arguments on this theoretical account by Minster, Elliffe, \& Muthukumaraswamy, 2011; Tonneau, 2001; Tonneau, Arreola, \& Martínez, 2006; Tonneau \& González, 2004). However, results from the present study cannot be explained solely through stimulus associations because the $\mathrm{X}$ and $\mathrm{Y}$ stimuli were not paired or presented with a common stimulus.

For the reasons just outlined, and because the stimuli that become equivalent were not presented with the same temporal pattern, classic conditioning was not involved in this learning process. Instead, the observed outcome is better explained as being the result of a complex type of operant conditioning.

Another interesting question is whether the learning process shown here could be due to an associative process. As explained above, stimulus-stimulus relations are not involved. Other types of associative processes described consist of stimulus-reinforcer associations (e.g., Rescorla, 1992; Zentall, Wasserman, \& Urcuioli, 2014). Specific stimulusoutcome relations cannot explain class formation with the $\mathrm{X}$ and $\mathrm{Y}$ stimuli either. If fact, all the stimuli were equally related to reinforcement (see Fig. 1). Even more, all the $\mathrm{X}$ and $\mathrm{Y}$ stimuli were equally related to the remaining stimuli (as explained above). Therefore, it seems that the present results cannot be accounted for by some learning theories and may present a challenge to them. What is, then, the nature of the learning process? As described above, what made $\mathrm{X} 1$ and $\mathrm{Y} 1$ functionally equivalent, on the one hand, and $\mathrm{X} 2$ and $\mathrm{Y} 2$, on the other, was that they "indicated" doing the same as in their absence, or selecting the alternative comparison, respectively. This type of learning is derived from the complex relations taught among the stimuli in two conditional discriminations (e.g., $\mathrm{AB}$ and $\mathrm{XAB}$ ). If some associative process is to be invocated, this should include that the relations established in teaching were between stimuli and the relations themselves established among other stimuli. The process has similarities to the process described by Pérez-González (1994): Persons learned to select $\mathrm{X} 1$ or $\mathrm{X} 2$ in the presence of a simple relation that has been previously taught (e.g., select X1 in the presence of previously related $\mathrm{A} 1$ and $\mathrm{B} 1$ stimuli); they then learned an identical simple relation, but with another stimuli (e.g., relate P1 and Q1); finally, in probes without reinforcement, they selected X1 or X2 according to the relations established between the new stimuli (e.g., they selected X1 in the presence of P2 and Q2). Stimulus-stimulus associations or stimulusreinforcer associations cannot explain these data; instead, relations between stimuli (e.g., X1) and relations (equivalent or not equivalent) can. The learning process observed in the present study seems more complex than that observed in the Pérez-González study. In summary, the learning process observed in the present study cannot be explained by associative processes unless the relations themselves are taken as an associative element.

The results of Experiment 3 suggest that even though the probability of matching according to the order after the procedures used in the present study is low (it occurred in only 12 $\%$ of the participants) it is worth considering. Therefore, further studies should take this process into account for properly designing the teaching procedure when the research goal is to study only one of the two types of transfer demonstrated here.

The transfer of control processes described by PérezGonzález and Serna (2003) has been replicated once more. In this case, it has been replicated with auditory and visual stimuli. This fact demonstrates that the type of transfer is cross-modal. In other words, the sensory modality of the stimuli plays a secondary role as transfer occurs with stimuli of the same modality as with stimuli of a different modality.

The procedure used in the present study involved providing the participants with some basic instructions and the use of an errorless procedure, which in fact made it possible for the participants to learn with very few errors. Although we minimized the instructions and tried to avoid participant verbalizations, it is very likely that the verbally sophisticated adults could use some kind covert behavior. Moreover, the errorless procedure could affect the final performance. In fact, the correlations between errors in learning and incorrect responses in the emergence probes (e.g., participant Ana in Experiment 1) suggest that errorless teaching can facilitate emergence. An argument contrary to this assumption is that the errorless procedure was not used to teach the initial contextually controlled conditional discriminations (e.g., XAB) in previous studies (e.g., Pérez-González \& Martínez, 2007; Pérez-González \& Serna, 2003). Moreover, it was not used to teach the simple conditional discriminations nor the contextually controlled conditional discriminations in Serna \& Pérez-González (2003). Thus, it is very likely that prompts are not necessary for, and therefore did not affect, the learning outcomes observed in the present study. The role of the instructions is more complex, because adults very likely make assumptions about the task. It is possible, however, that young children do not verbalize so much. Yet, they can show 
this type of transfer. Therefore, further studies with children will be very useful in clarifying this question.

An alternative explanation to the one relative to the role of language in the present data is that the learning processes are involved in the acquisition of language. Thus, the stimulus equivalence process described in the present study may be involved in many verbal processes. For example, the study suggests that if a person learns the function (meaning) of a word in a non-native language, that person could realize that the two words are equivalent. The equivalence can expand the repertoire of that person, because other functions (meaning or specific utilities of the word) in the native language can transfer to the word learned in the non-native language. For that reason, the procedures described in the present study can be applied in education, including teaching people with verbal learning difficulties, such as people with autism and Asperger syndrome.

Acknowledgments This research was supported by grant PSI200908644 from the Ministerio de Ciencia e Innovación, Spain, to the first author, who directed the study. The other three authors contributed approximately equally. The authors thank two anonymous reviewers of previous versions of the manuscript, and Jeanne Speakman for editing the manuscript.

\section{Appendices}

Appendix A

Trials with prompt, trials to criterion, and correct responses and trials presented to each participant in the first session (or sessions in the case of Ana) of Experiment 1

\begin{tabular}{|c|c|c|c|c|c|c|}
\hline \multirow[t]{2}{*}{ Phase and relation } & \multirow[t]{2}{*}{ Prompt } & \multirow[t]{2}{*}{ Criterion } & \multicolumn{4}{|c|}{ Participant and session } \\
\hline & & & $\begin{array}{c}\text { Nico } \\
1\end{array}$ & $\begin{array}{c}\text { Jose } \\
1\end{array}$ & $\begin{array}{c}\text { Ana } \\
1\end{array}$ & $\begin{array}{r}\text { Ana } \\
2\end{array}$ \\
\hline \multicolumn{7}{|l|}{ Part 1: AB Teaching } \\
\hline 1. A1-B1 & 2 & 3 & $5 / 5$ & $5 / 5$ & $5 / 5$ & $5 / 5$ \\
\hline 2. A2-B2 & 2 & 3 & $5 / 5$ & $5 / 5$ & $5 / 5$ & $5 / 5$ \\
\hline 3. $\mathrm{A} 1-\mathrm{B} 1 \& \mathrm{~A} 2-\mathrm{B} 2$ & 0 & 8 & $8 / 8$ & $8 / 9$ & $8 / 8$ & $8 / 8$ \\
\hline $\begin{array}{l}\text { 4. A1-B1 \& A2-B2 } \\
\text { - Random } \\
\text { Part 2: XAB Teaching }\end{array}$ & 0 & 8 & $8 / 9$ & $8 / 8$ & $8 / 8$ & $8 / 8$ \\
\hline 1. X1A1-B1 & 2 & 3 & $5 / 5$ & $5 / 5$ & $5 / 5$ & $5 / 5$ \\
\hline 2. X1A2-B2 & 2 & 3 & $5 / 5$ & $5 / 5$ & $5 / 5$ & $5 / 5$ \\
\hline $\begin{array}{l}\text { 3. X1A1-B1 \& } \\
\text { X1A2-B2 }\end{array}$ & 0 & 8 & $8 / 8$ & $11 / 15$ & $8 / 8$ & $8 / 8$ \\
\hline $\begin{array}{l}\text { 4. X1A1-B1 \& } \\
\text { X1A2-B2 - } \\
\text { Random }\end{array}$ & 0 & 8 & $8 / 8$ & $8 / 8$ & $8 / 8$ & $8 / 8$ \\
\hline 5. $\mathrm{X} 2 \mathrm{~A} 1-\mathrm{B} 2$ & 2 & 3 & $5 / 5$ & $5 / 5$ & $5 / 7$ & $5 / 5$ \\
\hline 6. X2A2-B1 & 2 & 3 & $5 / 5$ & $5 / 5$ & $5 / 5$ & $5 / 5$ \\
\hline $\begin{array}{l}\text { 7. X2A1-B2 \& } \\
\text { X2A2-B1 }\end{array}$ & 0 & 8 & $9 / 10$ & $8 / 8$ & $8 / 8$ & $8 / 8$ \\
\hline
\end{tabular}

\begin{tabular}{lllllll} 
8. X2A1-B2 \& & 0 & 8 & $8 / 8$ & $8 / 9$ & $8 / 8$ & $8 / 8$ \\
X2A2B1 - & & & & & & \\
Random & & & & & & \\
9. X1A1-B1, & 0 & 8 & $8 / 8$ & $8 / 8$ & $8 / 37$ & $8 / 8$ \\
$\quad$ X1A2-B2, & & & & & & \\
X2A1-B2, \& & & & & & & \\
$\quad$ X2A2-B1 & & & & & & \\
Part 5: CD Teaching & & & & & & \\
1. C1-D1 & 2 & 3 & $5 / 5$ & $5 / 5$ & $5 / 5$ & $5 / 5$ \\
2. C2-D2 & 2 & 3 & $5 / 5$ & $5 / 5$ & $5 / 5$ & $5 / 5$ \\
3. C1-D1 \& C2-D2 & 0 & 8 & $8 / 8$ & $8 / 8$ & $8 / 8$ & $8 / 8$ \\
4. C1-D1 \& C2-D2 & 0 & 8 & $8 / 8$ & $8 / 8$ & $8 / 8$ & $8 / 8$ \\
$\quad$ - Random & & & & & & \\
Part 6: XCD Probe & & & & & & \\
1. X1C1-D1, & 0 & - & $16 / 16$ & $16 / 16$ & $9 / 16$ & $16 / 16$ \\
X1C2-D2, & & & & & & \\
X2C1-D2 \& & & & & & & \\
X2C2-D1 & & & & & & \\
\hline
\end{tabular}

\section{Appendix B}

Correct responses and trials presented to each participant in the last session of Experiment 1

\begin{tabular}{|c|c|c|c|}
\hline \multirow[t]{2}{*}{ Phase and relation } & \multicolumn{3}{|c|}{ Participant } \\
\hline & Nico & Jose & Ana \\
\hline \multicolumn{4}{|l|}{ Part 1: AB Teaching } \\
\hline 1. A1-B1 & $5 / 5$ & $5 / 5$ & $5 / 5$ \\
\hline 2. A2-B2 & $5 / 5$ & $5 / 5$ & $5 / 5$ \\
\hline 3. $\mathrm{A} 1-\mathrm{B} 1 \& \mathrm{~A} 2-\mathrm{B} 2$ & $8 / 8$ & $8 / 8$ & $8 / 8$ \\
\hline 4. A1-B1 \& A2-B2 - Random & $8 / 8$ & $8 / 8$ & $8 / 8$ \\
\hline \multicolumn{4}{|l|}{ Part 2: XAB Teaching } \\
\hline 1. X1A1-B1 & $5 / 5$ & $5 / 5$ & $5 / 5$ \\
\hline 2. X1A2-B2 & $5 / 5$ & $5 / 5$ & $5 / 5$ \\
\hline 3. X1A1-B1 \& X1A2-B2 & $8 / 8$ & $8 / 8$ & $8 / 8$ \\
\hline 4. X1A1-B1 \& X1A2-B2 - Random & $8 / 8$ & $8 / 8$ & $8 / 8$ \\
\hline 5. X2A1-B2 & $5 / 5$ & $5 / 5$ & $5 / 5$ \\
\hline 6. X2A2-B1 & $5 / 5$ & $5 / 5$ & $5 / 5$ \\
\hline 7. X2A1-B2 \& X2A2-B1 & $8 / 8$ & $8 / 8$ & $8 / 8$ \\
\hline 8. X2A1-B2 \& X2A2-B1 - Random & $8 / 8$ & $8 / 8$ & $8 / 8$ \\
\hline 9. X1A1-B1, X1A2-B2, X2A1-B2, \& X2A2-B1 & $8 / 8$ & $8 / 8$ & $8 / 9$ \\
\hline \multicolumn{4}{|l|}{ Part 3: CD Teaching } \\
\hline 1. C1-D1 & $5 / 5$ & $5 / 5$ & $5 / 5$ \\
\hline 2. C2-D2 & $5 / 5$ & $5 / 5$ & $5 / 5$ \\
\hline 3. C1-D1 \& C2-D2 & $8 / 8$ & $8 / 8$ & $8 / 8$ \\
\hline 4. C1-D1 \& C2-D2 - Random & $8 / 8$ & $8 / 8$ & $8 / 8$ \\
\hline \multicolumn{4}{|l|}{ Part 4: XCD Probe } \\
\hline 1. X1C1-D1, X1C2-D2, X2C1-D2, \& X2C2-D1 & $16 / 16$ & $16 / 16$ & $16 / 16$ \\
\hline \multicolumn{4}{|l|}{ Part 5: HJ Teaching } \\
\hline 1. H1-J1 & $5 / 5$ & $5 / 5$ & $5 / 5$ \\
\hline 2. H2-J2 & $5 / 5$ & $5 / 5$ & $5 / 5$ \\
\hline 3. H1-J1 \& H2-J2 & $8 / 8$ & $8 / 8$ & $8 / 8$ \\
\hline
\end{tabular}




\begin{tabular}{lccc} 
4. H1-J1 \& H2-J2 - Random & $8 / 8$ & $8 / 8$ & $8 / 8$ \\
Part 6: YHJ Teaching & & & \\
1. Y1H1-J1 & $5 / 5$ & $5 / 5$ & $5 / 5$ \\
2. Y1H2-J2 & $5 / 5$ & $5 / 5$ & $5 / 5$ \\
3. Y1H1-J1 \& Y1H2-J2 & $8 / 8$ & $8 / 8$ & $8 / 8$ \\
4. Y1H1-J1 \& Y1H2-J2 - Random & $8 / 8$ & $8 / 8$ & $8 / 8$ \\
5. Y2H1-J2 & $5 / 5$ & $5 / 5$ & $5 / 5$ \\
6. Y2H2-J1 & $5 / 5$ & $5 / 5$ & $5 / 5$ \\
7. Y2H1-J2 \& Y2H2-J1 & $8 / 8$ & $8 / 8$ & $8 / 8$ \\
8. Y2H1-J2 \& Y2H2-J1 - Random & $8 / 8$ & $8 / 8$ & $8 / 8$ \\
9. Y1H1-J1, Y1H2-J2, Y2H-J2, \& Y2H2-J1 & $8 / 8$ & $8 / 8$ & $8 / 8$ \\
Part 7: KL Teaching & & & \\
1. K1-L1 & $5 / 5$ & $5 / 5$ & $5 / 5$ \\
2. K2-L2 & $5 / 5$ & $5 / 5$ & $5 / 5$ \\
3. K1-L1 \& K2-L2 & $8 / 8$ & $8 / 8$ & $8 / 8$ \\
4. K1-L1 \& K2-L2 - Random & $8 / 8$ & $8 / 8$ & $8 / 8$ \\
Part 8: YKL Probe & & & \\
1. Y1K1-L1, Y1K2-L2, Y2K1-L2, \& Y2K2-L1 & $16 / 16$ & $16 / 16$ & $16 / 16$ \\
Part 9: XY Probe & & & \\
1. X1-Y1 \& X2-Y2 & $16 / 16$ & $16 / 16$ & $16 / 16$ \\
\hline
\end{tabular}

Appendix C

Correct responses and trials presented to each participant in Experiment 2

\begin{tabular}{|c|c|c|c|}
\hline \multirow[t]{2}{*}{ Phase and relation } & \multicolumn{3}{|c|}{ Participant } \\
\hline & Camilo & Julio & Sara \\
\hline \multicolumn{4}{|l|}{ Part 1: AB Teaching } \\
\hline 1. A1-B1 & $5 / 5$ & $5 / 5$ & $5 / 5$ \\
\hline 2. A2-B2 & $5 / 5$ & $5 / 5$ & $5 / 5$ \\
\hline 3. A1-B1 \& A2-B2 & $8 / 8$ & $12 / 16$ & $9 / 12$ \\
\hline 4. A1-B1 \& A2-B2 - Random & $8 / 8$ & $8 / 8$ & $9 / 10$ \\
\hline \multicolumn{4}{|l|}{ Part 2: XAB Teaching } \\
\hline 1. X1A1-B1 & $5 / 5$ & $5 / 5$ & $5 / 5$ \\
\hline
\end{tabular}

\begin{tabular}{|c|c|c|c|}
\hline 2. X1A2-B2 & $5 / 5$ & $5 / 5$ & $5 / 5$ \\
\hline 3. X1A1-B1 \& X1A2-B2 & $8 / 8$ & $8 / 8$ & $9 / 10$ \\
\hline 4. X1A1-B1 \& X1A2-B2 - Random & $8 / 8$ & $8 / 8$ & $8 / 8$ \\
\hline 5. X2A1-B2 & $5 / 5$ & $5 / 5$ & $5 / 5$ \\
\hline 6. X2A2-B1 & $5 / 5$ & $5 / 5$ & $5 / 5$ \\
\hline 7. X2A1-B2 \& X2A2-B1 & $8 / 8$ & $10 / 12$ & $8 / 8$ \\
\hline 8. X2A1-B2 \& X2A2-B1 - Random & $8 / 8$ & $21 / 29$ & $8 / 8$ \\
\hline 9. X1A1-B1, X1A2-B2, X2A1-B2, \& X2A2-B1 & $8 / 8$ & $8 / 8$ & $8 / 8$ \\
\hline \multicolumn{4}{|l|}{ Part 3: HJ Teaching } \\
\hline 1. H1-J1 & $5 / 5$ & $5 / 5$ & $5 / 5$ \\
\hline 2. H2-J2 & $5 / 5$ & $5 / 5$ & $5 / 5$ \\
\hline 3. H1-J1 \& H2-J2 & $8 / 8$ & $8 / 8$ & $8 / 8$ \\
\hline 4. H1-J1 \& H2-J2 - Random & $8 / 8$ & $8 / 8$ & $8 / 8$ \\
\hline \multicolumn{4}{|l|}{ Part 4: YHJ Teaching } \\
\hline 1. Y1H1-J1 & $5 / 5$ & $5 / 5$ & $5 / 5$ \\
\hline 2. Y1H2-J2 & $5 / 5$ & $5 / 5$ & $5 / 5$ \\
\hline 3. Y1H1-J1 \& Y1H2-J2 & $8 / 8$ & $8 / 8$ & $8 / 8$ \\
\hline 4. Y1H1-J1 \& Y1H2-J2 - Random & $8 / 8$ & $8 / 8$ & $8 / 8$ \\
\hline 5. Y2H1-J2 & $5 / 5$ & $5 / 5$ & $5 / 5$ \\
\hline 6. $\mathrm{Y} 2 \mathrm{H} 2-\mathrm{J} 1$ & $5 / 5$ & $5 / 5$ & $5 / 5$ \\
\hline 7. Y2H1-J2 \& Y2H2-J1 & $8 / 8$ & $8 / 8$ & $8 / 8$ \\
\hline 8. Y2H1-J2 \& Y2H2-J1 - Random & $8 / 8$ & $8 / 8$ & $8 / 8$ \\
\hline \multicolumn{4}{|l|}{ Part 5: YHJ Teaching } \\
\hline 1. Y1H1-J1, Y1H2-J2, Y2H1-J2, \& Y2H2-J1 & $8 / 8$ & $8 / 8$ & $8 / 8$ \\
\hline \multicolumn{4}{|l|}{ Part 6: XY Probe } \\
\hline 1. X1-Y1 \& X2-Y2 & $16 / 16$ & $14 / 16$ & $13 / 16$ \\
\hline
\end{tabular}

\section{Appendix D}

Correct responses and trials presented to each participant in Experiment 3. The number that follows the participant's name indicates the condition they received; in the next line (a) the age in years and sex (m: male; f: female), (b) the Y stimulus presented first (Y1 or Y2), (c) the drawing assigned to Y1 (A or $\mathrm{B}$ ), and (d) the sound stimulus assigned to $\mathrm{X} 1$ are shown

\begin{tabular}{|c|c|c|c|c|c|c|c|c|}
\hline \multirow[b]{2}{*}{ Phase and relation } & \multicolumn{8}{|c|}{ Participant and condition } \\
\hline & $\begin{array}{l}\text { Flora-1 } \\
23-\mathrm{F} \\
\text { Y1 } \\
\text { A } \\
\text { [train] }\end{array}$ & $\begin{array}{l}\text { Sara-2 } \\
18-\mathrm{F} \\
\text { Y1 } \\
\text { A } \\
\text { [glass] }\end{array}$ & $\begin{array}{l}\text { Lola-3 } \\
23-\mathrm{F} \\
\text { Y1 } \\
\text { B } \\
\text { [train] }\end{array}$ & $\begin{array}{l}\text { Andrea-4 } \\
22-\mathrm{F} \\
\text { Y1 } \\
\mathrm{B} \\
\text { [glass] }\end{array}$ & $\begin{array}{l}\text { David-5 } \\
18-\mathrm{M} \\
\text { Y2 } \\
\text { A } \\
\text { [train] }\end{array}$ & $\begin{array}{l}\text { Alba-6 } \\
20-\mathrm{F} \\
\text { Y2 } \\
\text { A } \\
\text { [glass] }\end{array}$ & $\begin{array}{l}\text { Mario-7 } \\
22-\mathrm{M} \\
\text { Y2 } \\
\text { B } \\
\text { [train] }\end{array}$ & $\begin{array}{l}\text { Sara-8 } \\
23-\mathrm{F} \\
\text { Y2 } \\
\text { B } \\
\text { [glass] }\end{array}$ \\
\hline \multicolumn{9}{|l|}{ Part 1: AB Teaching } \\
\hline 1. A1-B1 & $5 / 5$ & $5 / 5$ & $5 / 5$ & $5 / 5$ & $5 / 5$ & $5 / 5$ & $5 / 5$ & $5 / 5$ \\
\hline 2. A2-B2 & $5 / 5$ & $5 / 5$ & $5 / 5$ & $5 / 5$ & $5 / 5$ & $5 / 5$ & $5 / 5$ & $5 / 5$ \\
\hline 3. $\mathrm{A} 1-\mathrm{B} 1 \& \mathrm{~A} 2-\mathrm{B} 2$ & $8 / 8$ & $15 / 16$ & $8 / 8$ & $12 / 20$ & $8 / 8$ & $23 / 32$ & $8 / 8$ & $8 / 8$ \\
\hline 4. A1-B1 \&A2-B2 - Random & $8 / 8$ & $8 / 8$ & $8 / 8$ & $8 / 8$ & $8 / 8$ & $8 / 8$ & $8 / 8$ & $8 / 8$ \\
\hline
\end{tabular}




\begin{tabular}{|c|c|c|c|c|c|c|c|c|}
\hline \multicolumn{9}{|l|}{ Part 2: XAB Teaching } \\
\hline 1. X1A1-B1 & $5 / 5$ & $5 / 5$ & $5 / 5$ & $5 / 5$ & $5 / 5$ & $5 / 5$ & $5 / 5$ & $5 / 5$ \\
\hline 2. $\mathrm{X} 1 \mathrm{~A} 2-\mathrm{B} 2$ & $5 / 5$ & $5 / 5$ & $5 / 5$ & $5 / 5$ & $5 / 5$ & $5 / 5$ & $5 / 5$ & $5 / 5$ \\
\hline 3. X1A1-B1 \& X1A2-B2 & $8 / 8$ & $8 / 9$ & $8 / 8$ & $8 / 8$ & $8 / 8$ & $8 / 8$ & $8 / 8$ & $8 / 8$ \\
\hline 4. X1A1-B1 \& X1A2 -B2 - Random & $8 / 8$ & $8 / 8$ & $8 / 8$ & $8 / 8$ & $8 / 8$ & $8 / 8$ & $8 / 8$ & $8 / 8$ \\
\hline 5. X2A1-B2 & $5 / 5$ & $5 / 5$ & $5 / 5$ & $5 / 5$ & $5 / 5$ & $5 / 5$ & $5 / 5$ & $5 / 5$ \\
\hline 6. X2 A2-B1 & $5 / 5$ & $5 / 5$ & $5 / 5$ & $5 / 5$ & $5 / 5$ & $5 / 5$ & $5 / 5$ & $5 / 5$ \\
\hline 7. $\mathrm{X} 2 \mathrm{~A} 1-\mathrm{B} 2 \& \mathrm{X} 2 \mathrm{~A} 2-\mathrm{B} 1$ & $8 / 8$ & $15 / 16$ & $8 / 8$ & $8 / 8$ & $8 / 8$ & $8 / 8$ & $8 / 8$ & $8 / 8$ \\
\hline 8. X2A1-B2 \& X2A2 -B1 - Random & $8 / 8$ & $8 / 8$ & $8 / 8$ & $8 / 8$ & $8 / 8$ & $8 / 8$ & $8 / 8$ & $8 / 8$ \\
\hline 9. X1A1-B1, X1A2-B2, X2A1-B2 \& X2A2-B1 & $8 / 8$ & $14 / 17$ & $8 / 8$ & $8 / 8$ & $18 / 20$ & $15 / 17$ & $8 / 10$ & $8 / 8$ \\
\hline \multicolumn{9}{|l|}{ Part 3: HJ Teaching } \\
\hline 1. H1-J1 & $5 / 5$ & $5 / 5$ & $5 / 5$ & $5 / 5$ & $5 / 5$ & $5 / 5$ & $5 / 5$ & $5 / 5$ \\
\hline 2. $\mathrm{H} 2-\mathrm{J} 2$ & $5 / 5$ & $5 / 5$ & $5 / 5$ & $5 / 5$ & $5 / 5$ & $5 / 5$ & $5 / 5$ & $5 / 5$ \\
\hline 3. H1-J1 \& H2-J2 & $8 / 8$ & $8 / 8$ & $8 / 8$ & $8 / 8$ & $11 / 13$ & $8 / 8$ & $8 / 8$ & $8 / 8$ \\
\hline 4. H1-J1 \& H2-J2 - Random & $8 / 8$ & $8 / 8$ & $8 / 8$ & $8 / 8$ & $8 / 8$ & $8 / 8$ & $8 / 8$ & $8 / 8$ \\
\hline \multicolumn{9}{|l|}{ Part 4: YHJ Teaching } \\
\hline 1. Y1H1-J1 & $5 / 5$ & $5 / 5$ & $5 / 5$ & $5 / 5$ & & & & \\
\hline 2. $\mathrm{Y} 1 \mathrm{H} 2-\mathrm{J} 2$ & $5 / 5$ & $5 / 5$ & $5 / 5$ & $5 / 5$ & & & & \\
\hline 3. Y1H1-J1 \& Y1H2-J2 & $8 / 8$ & $8 / 8$ & $8 / 8$ & $8 / 8$ & & & & \\
\hline 4. Y1H1-J1 \& Y1H2-J2 - Random & $8 / 8$ & $8 / 8$ & $8 / 8$ & $8 / 8$ & & & & \\
\hline 5. Y2H1-J2 & $5 / 5$ & $5 / 5$ & $5 / 5$ & $5 / 5$ & $5 / 5$ & $5 / 5$ & $5 / 5$ & $5 / 5$ \\
\hline 6. $\mathrm{Y} 2 \mathrm{H} 2-\mathrm{J} 1$ & $5 / 5$ & $5 / 5$ & $5 / 5$ & $5 / 5$ & $5 / 5$ & $5 / 5$ & $5 / 5$ & $5 / 5$ \\
\hline 7. Y2H1-J2 \& Y2H2-J1 & $8 / 8$ & $8 / 8$ & $8 / 8$ & $8 / 8$ & $8 / 8$ & $8 / 8$ & $8 / 8$ & $8 / 8$ \\
\hline 8. Y2H1-J2 \& Y2H2-J1 - Random & $8 / 8$ & $8 / 8$ & $8 / 8$ & $8 / 8$ & $8 / 8$ & $8 / 8$ & $8 / 8$ & $8 / 8$ \\
\hline 9. Y1H1-J1 & & & & & $5 / 5$ & $5 / 5$ & $5 / 5$ & $5 / 5$ \\
\hline 10. $\mathrm{Y} 1 \mathrm{H} 2-\mathrm{J} 2$ & & & & & $5 / 5$ & $5 / 5$ & $5 / 5$ & $5 / 5$ \\
\hline 11. Y1H1-J1 \& Y1H2-J2 & & & & & $8 / 8$ & $8 / 8$ & $8 / 8$ & $8 / 8$ \\
\hline 12. Y1H1-J1 \& Y1H2-J2 - Random & & & & & $8 / 8$ & $8 / 8$ & $8 / 8$ & $8 / 8$ \\
\hline 13. Y1H1-J1, Y1H2-J2, Y2H1-J2 \& Y2H2-J1 & $8 / 8$ & $8 / 8$ & $8 / 8$ & $8 / 8$ & $8 / 8$ & $8 / 8$ & $8 / 8$ & $8 / 8$ \\
\hline \multicolumn{9}{|l|}{ Part 5: XY Probe } \\
\hline 1.X1-Y1 \& X2-Y2 & $16 / 16$ & $16 / 16$ & $16 / 16$ & $16 / 16$ & $0 / 16$ & $16 / 16$ & $16 / 16$ & $16 / 16$ \\
\hline Total & $188 / 188$ & $208 / 214$ & $188 / 188$ & $192 / 200$ & $185 / 205$ & $210 / 221$ & $188 / 190$ & $188 / 188$ \\
\hline
\end{tabular}

\section{References}

Carpentier, F., Smeets, P. M., \& Barnes-Holmes, D. (2000). Matching compound samples with unitary comparisons: Derived stimulus relations in adults and children. The Psychological Record, 50, 671685.

Carpentier, F., Smeets, P. M., \& Barnes-Holmes, D. (2002a). Establishing transfer of compound control in children: A stimulus control analysis. The Psychological Record, 52, 139-158.

Carpentier, F., Smeets, P. M., \& Barnes-Holmes, D. (2002b). Matching functionally same relations: Implications for equivalenceequivalence as a model for analogical reasoning. The Psychological Record, 52, 351-370.

Harlow, H. F. (1949). The formation of learning sets. Psychological Review, 56, 51-65. doi:10.1037/h0062474

Honey, R. C., \& Watt, A. (1999). Acquired relational equivalence between contexts and features. Journal of Experimental Psychology: Animal Behavior Processes, 25, 324-333. doi:10.1037/0097-7403. 25.3.324

Junior, J. L., \& Costa, G. G. (2003). Efeitos das respostas de observação diferenciais sobre a aprendizagem de relações condicionais com estímulos complexos [Effects of differential observing responses over the learning of conditional relations with complex stimuli]. Psicologia: Reflexão e Crítica, 16, 71-84.

Junior, J. L., Costa, G. G., Gonsales, L. F. S., \& Golfeto, R. M. (2001). Aprendizagem e emergência de relações condicionais com estímulos modelos complexos [Learning and emergence of conditional relations with complex sample stimuli]. In H. J. Guilhardi, M. B. Pinho Madi, P. Piazzon Queiroz, \& M. C. Scoz (Eds.), Sobre comportamento e cognição: Expondo a variabilidade (pp. 401421). Sao Paulo, Brazil: ESETec Editores Asociados.

Minster, S. T., Elliffe, D., \& Muthukumaraswamy, S. D. (2011). Emergent stimulus relations depend on stimulus correlation and not on reinforcement contingencies. Journal of the experimental analysis of behavior, 95, 327-342. doi:10.1901/jeab. 2011.95-327

Molet, M., Miller, H. C., \& Zentall, T. R. (2011). Acquired equivalence between stimuli trained in the same context. Psychonomic Bulletin \& Review, 18, 618-623. doi:10.3758/s13423-011-0087-8

Pérez-González, L. A. (1994). Transfer of relational stimulus control in conditional discriminations. Journal of the Experimental Analysis of Behavior, 61, 487-503. doi:10.1901/jeab. 1994.61-487

Pérez-González, L. A. (2008). Concept formation based on feature relations evaluated with a matching-to-sample procedure. Behavioural Processes, 77, 7-32. doi:10.1016/j.beproc.2007.05.008

Pérez-González, L. A., Álvarez, E., Calleja, A., \& Fernández, A. (2014). Transfer of three functions of contextual stimuli in conditional discriminations. The Psychological Record. Advanced online publication. doi:10.1007/s40732-014-0104-1

Pérez-González, L. A., \& Martínez, H. (2007). Control by contextual stimuli in novel second-order conditional discriminations. The Psychological Record, 57, 117-143.

Pérez-González, L. A., \& Serna, R. W. (2003). Transfer of specific contextual functions to novel conditional discriminations. Journal of the 
Experimental Analysis of Behavior, 79, 395-408. doi:10.1901/jeab. 2003.79-395

Pérez-González, L. A., Spradlin, J. E., \& Saunders, K. J. (2000). Learning-set outcome in second-order conditional discriminations. The Psychological Record, 50, 429-442.

Rescorla, R. A. (1992). Response-outcome versus outcome-response associations in instrumental learning. Animal Learning and Behavior, 20, 223-232.

Rodríguez-Mori, M., \& Pérez-González, L. A. (2005). A simple procedure to teach conditional discriminations to children. Experimental Analysis of Human Behavior Bulletin, 23, 3-6.

Saunders, K. J., \& Spradlin, J. E. (1990). Conditional discrimination in mentally retarded adults: The development of generalized skills. Journal of the Experimental Analysis of Behavior, 54, 239-250. doi:10.1901/jeab. 1990.54-239

Saunders, K. J., \& Spradlin, J. E. (1993). Conditional discrimination in mentally retarded adults: Programming acquisition and learning set. Journal of the Experimental Analysis of Behavior, 60, 571-585. doi: 10.1901/jeab. 1993.60-571

Saunders, R. R., Drake, K. M., \& Spradlin, J. E. (1999). Equivalence class establishment, expansion, and modification in preschool children. Journal of the Experimental Analysis of Behavior, 71, 195214. doi:10.1901/jeab. 1999.71-195

Serna, R. W., \& Pérez-González, L. A. (2003). Generalized contextual control of conditional discriminations and unreinforced conditional selection. Journal of the Experimental Analysis of Behavior, 79, 383-393. doi:10.1901/jeab. 2003. 79-383
Sidman, M. (1986). Functional analysis of emergent verbal classes. In T. Thompson \& M. D. Zeiler (Eds.), Analysis and integration of behavioral units (pp. 213-245). Hillsdale, NJ: Lawrence Erlbaum.

Sidman, M. (1994). Equivalence relations and behavior: A research story. Boston: Authors Cooperative.

Sidman, M., \& Tailby, W. (1982). Conditional discrimination vs. matching to sample: an expansion of the testing paradigm. Journal of the Experimental Analysis of Behavior, 37, 5-22. doi:10.1901/ jeab.1982.37-5

Tonneau, F. (2001). Equivalence relations: A critical analysis. European Journal of Behavior Analysis, 2, 1-33.

Tonneau, F., Arreola, F., \& Martínez, A. G. (2006). Function transformation without reinforcement. Journal of the Experimental Analysis of Behavior, 85, 393-405. doi:10.1901/jeab.2006.49-05

Tonneau, F., \& González, C. (2004). Function transfer in human operant experiments: The role of stimulus pairings. Journal of the Experimental Analysis of Behavior, 81, 239-255. doi:10.1901/jeab. 2004.81-239

Urcuioli, P. J., Zentall, T. R., \& DeMarse, T. (1995). Transfer to derived sample-comparison relations by pigeons following many-to-one versus one-to-many matching with identical training relations. The Quarterly Journal of Experimental Psychology, 48, 158-178. doi: 10.1080/14640749508401445

Vaughan, W. (1988). Formation of equivalence sets in pigeons. Journal of Experimental Psychology: Animal Behavior Processes, 14, 36-42. doi:10.1037/0097-7403.14.1.36

Zentall, T. R., Wasserman, E. A., \& Urcuioli, P. J. (2014). Associative concept learning in animals. Journal of the Experimental Analysis of Behavior, 101, 130-151. doi:10.1080/14640749508401445 